\title{
Impact of men's perception on family planning demand and uptake in Nigeria
}

\author{
ADANIKIN, Abiodun Idowu ${ }^{1,2}$; McGRATH, Nuala ${ }^{1,3}$; PADMADAS, Sabu S. ${ }^{1}$ \\ ${ }^{1}$ Department of Social Statistics and Demography and Centre for Global Health, Population, \\ Poverty and Policy, University of Southampton, UK \\ ${ }^{2}$ Department of Obstetrics and Gynaecology, Ekiti State University, Ado-Ekiti, Nigeria \\ ${ }^{3}$ Primary Care and Population Studies Academic Unit, Faculty of Medicine, University of \\ Southampton, UK
}

Address for correspondence:

A.I. Adanikin,

Department of Social Statistics and Demography,

University of Southampton, Highfield Campus

Southampton, SO17 1BJ, United Kingdom

Email: a.i.adanikin@soton.ac.uk 


\begin{abstract}
Objective: Evidence from the last three Demographic and Health Surveys (DHS) in Nigeria shows slow progress in family planning (FP) uptake, despite programmatic interventions. While socioeconomic and religious barriers continue to exist, psychosocial factors such as negative contraceptive perceptions by male partners may influence both spousal FP demand and use. Therefore, this research investigates the influence of male partners' contraceptive perceptions on spousal FP demand and use.
\end{abstract}

Methods: We analysed the couple dataset from the 2013 Nigeria DHS.

Results: One in five men held the perception that contraceptive use is women's business whereas two in five men reported that women who use family planning may become promiscuous, especially older men, those with no formal education, Muslims and residents in rural areas and northern region. Results from regression models, controlling for relevant sociodemographic characteristics, show that men's perception that contraception is women's business did not significantly influence FP demand. However, their fear that women who use family planning may become promiscuous was associated with lower odds of FP demand (AOR: 0.86; 95\% CI: 0.76-0.97) and increased the odds of traditional methods use (AOR: 1.34; 95\% CI: 1.01-1.79).

Conclusion: The findings direct the need to adopt targeted approach focusing on couples, and reorient policy and program efforts for FP counselling and behavioural changes in men.

Key words: Family Planning, Perceptions, Men, Nigeria 


\section{INTRODUCTION}

At the forefront of interventions aimed at improving sexual and reproductive health wellbeing in developing countries is the efforts to increase the use of modern contraceptives. This is justified in terms of evidence showing its association with fewer unintended pregnancies, decrease in the incidence of sexually transmitted infections including HIV and reduction in maternal and neonatal morbidity and mortality [1]. Post-2015, the Sustainable Development Goals (SDG) have also identified demand for family planning (FP) satisfied by modern contraceptive uptake as a measurable indicator of universal access to sexual and reproductive health care [2]. The uptake of FP is one of the critical developmental goals for improving maternal and child survival in low and middle-income countries [3].

In less developed nations, although there is a substantial increase in the number of women of reproductive ages desiring to control fertility, there is no proportionate increase in modern contraceptive use [4]. A key observation is male partners' resistance to FP that overtly or covertly impedes uptake and/or continuation [5]. Beyond the individual decision-making factors, reproductive behaviour is shaped by social and institutional norms and policies, and concentrating only on women at the individual level is insufficient [6]. There is a widespread social conviction that African women in marital or sexual unions should abide by their partner's decisions and wishes [7-9], believed to be crucial for ensuring stability in relationships.

This is especially true in a patriarchal society like Nigeria. Specifically, male partners in the country are dominant in household reproductive decisions [10]. A study conducted among mothers with Under-five children in southern Nigeria demonstrates evidence that more than one half of women whose partners object to FP discontinued contraceptive use [11]. Even in instances where the husband is silent about making a reproductive decision or task-shifts the decision, most women know that they are culturally bound to wait for their husbands to make up his mind and provide a definitive lead on the matter. More so, some women fear that they may be forced out of their marital union if their husbands uncover any covert use of contraceptives [12].

However, FP in Nigeria needs improvement. The country's modern contraceptive prevalence only increased from $3 \%$ to $10 \%$ over the last two decades [13]. The poor uptake of modern contraception has adverse demographic consequences in the country. For example, the estimated total population of 170 million growing at an annual rate of $2.8 \%$ will more than 
double its current size within the next 35 years [14]. Also, the nation's high fertility rate (5.5 children per woman) is one of the reasons for continued cycle of poverty (currently about $84 \%$ live below poverty line) and poor maternal health outcomes [13, 15, 16]. Therefore, ensuring that men support FP and are willing to allow spouses to use contraception may be critical.

Within Nigeria, negative FP perceptions by men have been reported. While some men perceive that they have no role in FP and that contraception is business only for women, others believe that contraceptive use can make women promiscuous $[12,17,18]$. However, little is known about how these perceptions influence spousal contraceptive demand and uptake of modern methods. We address this evidence gap in the present study. Our research question is: do men's perceptions about family planning influence wives' family planning demand and use in Nigeria? We hypothesise that men's perceptions about FP and their fear of the role of contraception in female promiscuity deter partner's demand for FP and uptake of modern contraceptive methods. The findings from this study can offer insights into one of the psychosocial barriers impeding FP progress in Nigeria and contribute to designing targeted behavioural FP interventions.

\section{DATA AND METHODS}

We analyse the couple's dataset from the 2013 Nigeria Demographic and Health Survey (DHS). DHS was coordinated by the Nigeria Population Commission (NPC), with assistance from Inner City Fund (ICF) Macro and supported through the United State Agency for International Development (USAID) funded DHS program [13]. The survey instrument consists of three sets of questionnaires: household, women and men. NDHS is based on a threestage stratified design consisting of 904 clusters, which yielded a nationally representative samples of 40,680 households. All women aged 15-49 years who were permanent residents or visitors who were present in the households a night before the survey were interviewed. In a sub-sample of households, all men aged 15-49 years who were permanent resident or a visitor the night before the survey were also interviewed. A total of 38,948 women and 17,359 men were interviewed. From the individual women and men datasets, the couple dataset was generated by linking the data of men and women who were married or reported to be in a union for a total of 8,658 couples. 
The study considered two primary outcomes -variables: (i) demand for FP and (ii) uptake of modern contraceptive methods among women with FP demand. Total demand for FP was estimated by considering women of reproductive ages (15-49), married or in sexual union, who are fecund, who are currently using or their sexual partner is using at least one traditional or modern contraceptive method and, those with unmet need for contraception [19]. Modern contraceptive methods are the use of pills, intrauterine device (IUD), injections, diaphragm, condom, female sterilization, implants, female condom and foam/jelly. Periodic abstinence, withdrawal methods and other folkloric methods were regarded as traditional methods [10].

In order to achieve the objectives, two sets of analyses with different sample size and outcomes of interest were undertaken. The population included in the first analysis was fecund couples and the outcome was demand for FP. In the second analysis, the study population was fecund couples with FP demand and the outcome variable was uptake of modern contraceptive methods.

\section{— Figure 1 about here -}

In the survey, respondents were asked about their future fertility preference, the preferred waiting time to next childbirth, for those who indicated a desire for another child, and the current use of contraception, if any. Based on their response, a binary variable was constructed to analyse demand for FP, considering respondents using contraception for either spacing or limiting and those with unmet need for spacing or limiting coded as 1 (demand present) and 0 otherwise (demand absent). For the uptake of modern contraceptive methods, a multinomial variable was constructed by recoding current use of contraception as modern methods, traditional (including folkloric) methods and no method. We decided to use the female response in assessing contraceptive uptake, motivated by the literature, specifically a comparative analysis of 23 DHS that reported that wives' response is of higher validity in determining contraceptive use than husbands' [20]. Before proceeding with the analysis, we estimated a Kappa coefficient to measure the concordance of couple's response.

The primary explanatory variable of interest is male partner's perceptions about contraception. In the DHS, the perception of the partner was assessed based on response to two statements: contraception is a woman's business and a man should not worry about it; secondly, women who use contraception may be promiscuous. The partner's response was recorded as 'agree', 'disagree’ or ‘don’t know'. 
Guided by the conceptual framework by Bertrand et al. and literature on the determinants of family planning use in the African context [21-23], the analysis considered a set of individual socio-demographic variables. These include women's characteristics (woman's age, highest educational level, number of living children including current pregnancy, her occupation, domicile, religion and household wealth), male partner's characteristics (male partner's age, educational level and occupation) and woman's decision-making power as a proxy of her social status. Woman's decision-making power was based on the assessment of women's responses to five specific questions including: who decides how the money she earns is spent, how her partner's money is spent, who decides on her health care, family visit and on major household purchases. The response options included self (woman), her husband or partner, joint decision and others. We recoded the response as 0 if she was not involved in the decision and 1 if she was involved in the decision making. To reduce the dimension of decision-making variables, we applied Principal Component Analysis (PCA) to the 5 questions contributing to woman's decision making power to create an index score to measure relative decision-making power [10].

An initial exploratory analysis was conducted to assess the bivariate association between outcome and predictor variables. We fitted four sequential logistic regression models to explore how the male partner's FP perception and other factors could determine a couple's demand for contraception. Model 1 included partner's FP perceptions, controlling for woman's sociodemographic characteristics. Model 2 added household economic status and Model 3 included woman's decision-making power. The final model (Model 4) controlled for the influence of men's characteristics. We then tested for interactions between place of residence and wealth, and women's educational and household wealth status. For the second outcome, multinomial logistic regression models were fitted, following an approach similar to binary logistic regression. The variables were initially screened for multicollinearity problems before considering in the regression.

\section{RESULTS}

Descriptive analysis

The mean age of women in sexual union was $28.0 \pm 6.9$ years and that of their male partners was $36.3 \pm 7.3$ years. Whereas $39 \%$ of the men were 40 years or older, only $6.1 \%$ of the women were 40 years or above. A third of the men were uneducated and about $14 \%$ had education at 
higher secondary level. For women, 45\% were uneducated and only $7 \%$ had a higher education. In about $96 \%$ of couples, both partners practice the same religion. The majority (63\%) of the men were Muslims and 34.8\% were Catholic/Protestants. About 65\% of couples lived in rural areas and 70\% resided in the northern region. The overall demand for FP was 34.5\%: among these $30.4 \%$ used a modern contraceptive method and 53.9\% had unmet need. FP demand varied between $56.7 \%$ and $25.2 \%$ respectively in the southern and northern Nigeria. The couple’s concordance of contraceptive use reporting was Kappa coefficient 0.33.

The male partners' characteristics by perceptions of contraception is summarised in Table 1. Although most male partners less than 30 years old believe that contraception was women business only, perception of female promiscuity with contraceptive use was more pronounced among older men aged 40 and above. In both instances, negative perceptions about contraception were higher among uneducated, rural residents and those from the northern region, and those practicing Islam.

\section{- Table 1 about here -}

Table 2 presents the descriptive analysis of men's contraceptive perception and spousal FP demand and uptake. Overall, 23\% of male partners agreed that contraception is women's business only while $73 \%$ disagreed. On the other hand, $42 \%$ felt that female using contraceptives may become promiscuous. When men's FP perception and their spouse's demand for contraception is considered, women's demand for contraception was affected by male partner's perception. There was an 8 percent statistically significant increase in contraceptive demand based on men's perception of their role in FP (36.5\% versus 29.2\%; $p<0.001)$. Similarly, women whose partner did not believe that contraception will make them promiscuous had 12 percent $(40.4 \%$ versus 28.2\%; $p<0.001)$ increase in FP demand than their counterparts.

\section{- Table 2 about here -}

Furthermore, Table 2 illustrates the relationship between male partner's perception about FP and spousal uptake of contraception. About 62\% and 59\% of women respectively who had FP demand but whose partner responded that men have no role in FP or that contraception would make a woman promiscuous did not adopt any form of contraception. When a man acknowledges that contraception is not a woman's responsibility alone, the spousal use of modern methods increased by $10 \%$ more than to women whose partners perceive otherwise 
(32.9\% versus 23.2\%; $p<0.001$ ). Similarly, wives of those who did not believe that contraception will increase female promiscuity had highest uptake of modern method of contraception. They had a 7.5 percent increase in the uptake of modern methods compared to colleagues whose partners did believe that contraception will promote female promiscuity (34.2 versus $26.7 ; p<0.001)$.

Male partner's FP perception and spousal method choice is shown in Figure 2. Where the male partner felt that contraception is business for women only, 9.4\% of spouses reported using injectable, $5.7 \%$ oral pills and $4.6 \%$ male condoms. For the spouses whose husbands believe that using FP can make them become promiscuous, $11.6 \%$ had injectable, $4.9 \%$ used male condom and $4.5 \%$ relied on oral pills.

\section{- Figure 2 about here -}

\section{Regression analysis}

Table 3 reports the adjusted odds ratios from the logistics regression showing the influence of men's FP perceptions on their partner's FP demand. In the absence of controlling factors, both men's perception that FP is a business only for women and fear that contraception use promotes female promiscuity were significantly associated with lower odds of FP demand $(p<0.001)$. However, when the two variables were in the same model (model 0), only the indicator of fear that women will become promiscuous with the use of FP remained statistically associated with contraceptive demand. The odds of contraceptive demand was significantly lower where the male partners agreed with the perception (AOR 0.64, 95\% CI 0.59-0.72). Similarly, contraceptive demand was significantly lower among couples where the male partner answered 'don't know' compared to those who disagreed with the perception, (AOR 0.69, 95\% CI 0.55$0.86)$.

With demographic characteristics of the woman, the effect of the fear of female promiscuity on FP demand decreased to 0.84 relative to when the perception was absent, though it remained statistically significant (Model 1). The change in the magnitude of effect was explained by woman's level of education and number of living children. In other words, the more educated a woman is and the more the number of surviving children, the odds are less likely that men's negative perception of FP influences partner's FP need. When the women's demographic characteristics, household economic status and decision-making variables were considered 
(Model 2), the association between the male partner's fear of female promiscuity and FP demand was attenuated to AOR 0.86, 95\% CI (0.76-0.97) for those who agreed with the statement compared to those who disagreed. There was no longer a significant difference in the odds of FP demand between those who answered 'don't know' and those who disagreed with the perception. Women's decision-making power was not significantly associated with FP demand (Model 3) and this variable was not considered in subsequent models.

Two separate models were considered for the final model - the first adjusting for the individual male partner's characteristics and the second controlling for the couple's differential characteristics. Adjustment for partner's characteristics did not alter how the perception of female promiscuity with the use of contraception was associated with FP demand (shown as Model 4). Similarly, adjusting for differences in couple's age, educational level and number of living children did not change the magnitude or direction of the perception variables (result not shown). Test for interaction effects between place of residence and wealth, and women's educational and household wealth status were not significant.

\section{- Table 3 about here -}

The multinomial regression in Table 4 shows the relationship between partner's perception of contraception and the uptake of modern methods among women with FP demand. Although in the null model the perception of female promiscuity with the use of contraception was associated with reduced likelihood in uptake of modern contraception, the effect became nonsignificant in the model that controlled for woman's demographic characteristics (Model 1). Further data exploration showed evidence that woman's educational level mediated the effect of perception variables on contraceptive use. However, when household economic status was added, there was a change in the direction of effect (Model 2). Men's fear of female promiscuity increased the odds of use of traditional methods by women with FP demand and the effect was statistically significant (AOR: 1.34; 95\% CI: 1.01-1.78). The inclusion of women's decisionmaking (Model 3) and then men’s sociodemographic characteristics (Model 4) did not alter the effect. Woman's level of education, decision-making power and household wealth were strong predictors of modern contraceptive uptake. Partner's level of education and employment status had positive and significant effect on women's uptake of modern methods. 
A flip in the data analysis by directly relating the choice between traditional and modern contraceptive methods showed consistency in statistical inference - men's perception of their role in FP had no influence on method choice, however, men's fear that FP will promote female promiscuity reduced the odds of using modern methods (AOR: 0.73; 95\% CI: 0.54-0.97) compared to uptake of traditional methods.

\section{DISCUSSION AND CONCLUSION}

This paper examined the association between men's FP perception and spousal demand and use of contraceptives. Two indicators of men's perception toward FP were considered: those who believe that contraception is women's business only and those who feared that contraceptive use may lead to women becoming promiscuous. The foregoing analysis found evidence that one in five men in Nigeria held the perception that contraception is women's business whereas two in five men reported that women who use family planning may become promiscuous. Negative perception about FP was more among uneducated men, rural dwellers, those from northern part of the country and men practicing Islam. Although the opinion about men's role had no significant impact on FP demand and uptake, male partner's fear that contraceptive use will increase female promiscuity was associated with lower demand for contraception, after controlling for other important factors, and rather promoted the use of traditional methods among women with FP demand.

This research confirms our hypothesis that men's negative perceptions about FP influence women's contraceptive demand in Nigeria. As observed from the analysis, the belief that contraceptive use promotes promiscuity is popular among men. This perception is more pronounced among men from socially disadvantaged background, rural residents and those practicing Islam. Lutalo et al noted that cultural norms in rural areas could be barriers to contraceptive use [24]. It is possible that the ability of a woman to control her fertility is seen as key to her autonomy, which contradicts existing patriarchal system. It could make some men uncomfortable and inferior [12]. Therefore, the excuse female become promiscuous with the use of FP may be mere insinuation to curtail her autonomy regarding fertility.

Religion is considered to influence on attitudes towards FP [25]. Islamic tenet stipulates that a woman's consultation with her husband is necessary for any reproductive decision [26]. It means men's perception could translate to a veto regarding the use of contraception. In Nigeria 
there is evidence that knowledge of contraceptive methods has been subverted by Muslim religious rights on the grounds that it promote immorality [27]. Thus, it may not be a surprise that in this analysis a considerable proportion of Muslim men reported that the use of FP would promote female promiscuity. Furthermore, the observed discordance in couple's reporting of contraceptive use could suggest possible covert contraceptive uptake by some women.

Women's decision-making power and social position have been cited as important determinants of modern contraceptive use $[28,29]$. This study found that a woman's decisionmaking power did not enhance her demand for FP especially when the partner held the belief that contraception can make her promiscuous. However, for those with an existing FP demand, good decision power promoted the uptake of modern contraception.

Our study is the first of its kind in the Nigerian context to control for the effect of women's decision-making power while studying the relationship between men's FP perceptions and women's FP demand and use. Previously, Desai and Johnson had noted that in different scenario, historical and cultural peculiarities can superimpose on the resultant health benefit of a woman's autonomy to make decision [30]. Therefore, our research observation that a woman's involvement in decision-making did not enhance her demand for FP in Nigeria may be due to overriding socio-cultural influence.

Since men acknowledge their role in FP, changing their perception that contraception will promote promiscuity is pertinent. Specifically, this research demonstrates the need for policy interventions that will correct men's opinion that contraception promotes female promiscuity if FP demand will improve in Nigeria. The findings direct the need to adopt a targeted approach focusing on couples, and reorient policy and program efforts for FP counselling and behavioural changes in men. Indeed locally directed, content specific behavioural interventions focusing on sub-groups of men with negative perceptions about FP are imperative. FP interventions should consider generating culturally appropriate programmes aimed at demystifying the myth and negative perceptions about FP, exclusively targeting men of different age cohorts, rural residents, poorly educated and specific religious groups, e.g. Muslims. Such interventions are usually effective when led by community and religious leaders in community forum events held in town hall meetings, farmers' union gathering, churches and mosques, and by mass media [31].

Policy makers will need to go beyond promoting mere knowledge of contraception to enhancing positive perceptions of it. These interventions can be promoted early at the school 
and college levels so that future sexual and marital unions can be salvaged from negative notions that impact FP demand and use. More importantly, as shown in the analysis, female education and upper wealth status remain consistent predictors in improving both the demand for FP and uptake of modern contraception. Targeting females for quality education and empowering them economically is likely to reduce the effect of men's negative contraceptive perception over time.

This research contributes to building the evidence base of policy relevant factors influencing low modern contraceptive uptake in Nigeria. It brings a novelty to the sequence of its analysis in understanding some of the factors responsible for poor modern contraceptive uptake in the country. However, as with most secondary cross-sectional data, the extent of information available for the analysis were restricted. We could not measure other FP perceptions that could affect contraceptive use, such as, male perception about side effects, convenience and comfort factors that disrupts sexual intimacy and enjoyment, and fear of infertility. Also, we need panel data to understand how these perceptions change over time. Similarly, the survey responses on perceptions could likely be under-estimated because of cultural inhibitions and social desirability biases. Notwithstanding, the findings presented in this study provide valuable clues for policy and programme interventions for improving FP demand and modern contraceptive uptake in Nigeria.

\section{Conflict of interest}

The authors declare no conflict of interest.

Funding: This work was supported by the Commonwealth Scholarship Commission, United Kingdom

\section{REFERENCES}

1. Berhane Y, Tsui A, editors. Linking Reproductive Health, Family Planning and HIV/AIDS in Africa. International Conference on Linking Reproductive Health, Family Planning and HIV/AIDS in Africa; 2006.

2. Choi Y, Fabic MS, Hounton S, Koroma D. Meeting demand for family planning within a generation: prospects and implications at country level. GLOBAL HEALTH ACTION. 2015;8:3-12. 
3. Chola L, McGee S, Tugendhaft A, Buchmann E, Hofman K. Scaling up family planning to reduce maternal and child mortality: the potential costs and benefits of modern contraceptive use in South Africa. Plos One. 2015; 10(6): e1030077.

4. Darroch JE, Singh S. Trends in contraceptive need and use in developing countries in 2003, 2008, and 2012: an analysis of national surveys. The Lancet. 2013;381(9879):1756-62.

5. Miller W, Severy L, Pasta D. A framework for modelling fertility motivation in couples. Population Studies. 2004;58(2):193-205.

6. Price NL, Hawkins K. A conceptual framework for the social analysis of reproductive health. Journal of Health, Population and Nutrition. 2007:24-36.

7. Mesfin $\mathrm{G}$. The role of men in fertility and family planning program in Tigray Region. Ethiopian Journal of Health Development. 2002;16(3):247-55.

8. Eliason S, Baiden F, Quansah-Asare G, Graham-Hayfron Y, Bonsu D, Phillips J, et al. Factors influencing the intention of women in rural Ghana to adopt postpartum family planning. Reprod Health. 2013;10(1):34.

9. Palamuleni ME. Socio-economic and demographic factors affecting contraceptive use in Malawi. African journal of reproductive health. 2013;17(3):91-104.

10. OlaOlorun FM, Hindin MJ. Having a say matters: Influence of decision-making power on contraceptive use among Nigerian women ages 35-49 years. PloS one. 2014;9(6):e98702.

11. Nte AR, Odu N, Enyindah CE. Male Involvelment in family planning: women's perception. Nigerian Journal of Clinical Practice. 2009;12(3):306-10.

12. Okwor EU, Olaseha IO. Married men's perception about spousal use of modern contraceptives: a qualitative study in Ibadan northwest local government area, southwest Nigeria. International quarterly of community health education. 2010;30(3):223-38.

13. National Population Commission (NPC) [Nigeria] and ICF International. Nigeria Demographic and Health Survey 2013. Abuja, Nigeria and Rockville, Maryland, USA: NPC and ICF International.: 2014.

14. United Nations. World population prospects: the 2015 revision. 2015.

15. Hogan MC, Foreman KJ, Naghavi M, Ahn SY, Wang M, Makela SM, et al. Maternal mortality for 181 countries, 1980-2008: a systematic analysis of progress towards Millennium Development Goal 5. The lancet. 2010;375(9726):1609-23.

16. Nigeria Bureau of Statistics. Social Statistics in Nigeria 2012- Part III (Health, employment, public safety, population and vital registration) 2012 [cited 201625 September]. Available from: www.nigerianstat.gov.ng/pages/download/170.

17. Ogunjuyigbe PO, Akinlo A, Ebigbola JA. Violence against women: an examination of men's attitudes and perceptions about wife beating and contraceptive use. Journal of Asian and African Studies. 2005;40(3):219-29.

18. Akinso O, Akinso S. Factors that influence male involvement in family planning: a qualitative study of men of reproductive age in Ibadan North-East and North-West, Oyo State. Contraception. 2015;92(4):395.

19. World Health Organization. Demand for family planning satisfied with modern methods 2015 [cited 201629 April ]. Available from: http://www.who.int/healthinfo/indicators/2015/chi_2015_74_family_planning.pdf. 
20. Becker S, Costenbader E. Husbands' and wives' reports of contraceptive use. Studies in Family Planning. 2001:111-29.

21. Bertrand JT, Magnani RJ, Knowles JC. Handbook of indicators for family planning program evaluation. 1994.

22. Stephenson R, Baschieri A, Clements S, Hennink M, Madise N. Contextual influences on modern contraceptive use in sub-Saharan Africa. American journal of public health. 2007;97(7):1233-40.

23. Mohammed A, Woldeyohannes D, Feleke A, Megabiaw B. Determinants of modern contraceptive utilization among married women of reproductive age group in North Shoa Zone, Amhara Region, Ethiopia. Reproductive health. 2014;11(1):1.

24. Lutalo T, Kidugavu M, Wawer MJ, Serwadda D, Zabin LS, Gray RH. Trends and determinants of contraceptive use in Rakai District, Uganda, 1995-98. Studies in Family Planning. 2000;31(3):217-27.

25. Agadjanian V, Yabiku ST, Fawcett L. History, Community Milieu, and ChristianMuslim Differentials in Contraceptive Use in Sub-Saharan Africa. Journal for the Scientific Study of Religion. 2009;48(3):462-79.

26. Cook RJ, Maine D. Spousal veto over family planning services. American Journal of Public Health. 1987;77(3):339-44.

27. Iman A. Women, Muslim laws and human rights in Nigeria. Keynote address presented at the Woodrow Wilson International Center's Africa Program and Middle East Project on Women, Islam and Human Rights in Africa (September). 2003.

28. Woldemicael G. Women's autonomy and reproductive preferences in Eritrea. Journal of Biosocial Science. 2009;41(02):161-81.

29. Tadesse M, Teklie H, Yazew G, Gebreselassie F. Women's Empowerment as a Determinant of Contraceptive use in Ethiopia Further Analysis of the 2011 Ethiopia Demographic and Health Survey. DHS Further Analysis Reports. 2013(82).

30. Desai S, Johnson K. Women's Decisionmaking and Child Health: Familial and social hierarchies. A focus on gender: Collected papers on gender using DHS data. 2005:55-68.

31. Mwaikambo L, Speizer IS, Schurmann A, Morgan G, Fikree F. What works in family planning interventions: a systematic review. Studies in family planning. 2011;42(2):67-82. 
Table 1: Men's FP perceptions by their background characteristics (\%)

\begin{tabular}{|c|c|c|c|}
\hline Characteristics & Total & $\begin{array}{c}\text { Agrees contraception } \\
\text { is women's business } \\
\text { only (\%) }\end{array}$ & $\begin{array}{c}\text { Agrees female using } \\
\text { contraception may become } \\
\text { promiscuous (\%) }\end{array}$ \\
\hline Total & 7747 & 22.8 & 41.6 \\
\hline \multicolumn{4}{|l|}{ Male partner's age (years) } \\
\hline$<30$ & 1402 & 24.3 & 41.9 \\
\hline $30-39$ & 3362 & 22.4 & 40.5 \\
\hline$\geq 40$ & 2983 & 22.7 & 42.8 \\
\hline \multicolumn{4}{|l|}{ Highest educational level } \\
\hline No education & 2433 & 28.0 & 48.5 \\
\hline Primary & 1727 & 24.4 & 43.1 \\
\hline Secondary & 2453 & 19.5 & 37.1 \\
\hline Higher & 1134 & 15.3 & 32.8 \\
\hline \multicolumn{4}{|l|}{ Occupation } \\
\hline Unemployed & 100 & 21.7 & 28.8 \\
\hline Professional/Managerial & 962 & 17.5 & 36.4 \\
\hline Agricultural-based & 2893 & 25.1 & 42.0 \\
\hline Others & 3792 & 22.4 & 42.9 \\
\hline \multicolumn{4}{|l|}{ Place of residence } \\
\hline Urban & 2565 & 20.1 & 37.7 \\
\hline Rural & 5182 & 24.3 & 43.7 \\
\hline \multicolumn{4}{|l|}{ Religion } \\
\hline Catholic & 606 & 19.6 & 32.0 \\
\hline Protestant & 2376 & 15.5 & 29.4 \\
\hline Islam & 4623 & 26.3 & 48.1 \\
\hline Traditional/Others & 142 & 24.0 & 39.0 \\
\hline \multicolumn{4}{|l|}{ Region of residence } \\
\hline South & 2407 & 16.3 & 27.1 \\
\hline North & 5340 & 25.6 & 47.7 \\
\hline
\end{tabular}

The percentage is adjusted for sample weight 
Table 2: Men's contraceptive perception and spousal FP demand and uptake

\begin{tabular}{|c|c|c|c|c|c|c|c|}
\hline & \multirow[b]{2}{*}{ Agree } & \multicolumn{3}{|c|}{ Women business only } & \multicolumn{2}{|c|}{ Female becomes promiscuous } & \multirow{2}{*}{ Total } \\
\hline & & Disagree & Don't know & Agree & Disagree & Don't know & \\
\hline Overall & $1621(22.8)$ & $5805(73.1)$ & $321(4.1)$ & 3112(41.6) & $4050(50.4)$ & $585(8.0)$ & $7747(100)$ \\
\hline No FP demand & $1113(70.8)$ & 3642(63.5) & $227(71.4)$ & $2172(71.8)$ & 2404(59.6) & 406(69.6) & 4982(65.5) \\
\hline FP Demand & $508(29.2)$ & 2163(36.5) & $94(28.6)$ & $940(28.2)$ & $1646(40.4)$ & $179(30.4)$ & 2765(34.5) \\
\hline \multicolumn{8}{|c|}{$\begin{array}{l}\text { Contraceptive choice } \\
\text { by FP demand } \\
(n=2765)\end{array}$} \\
\hline None & $314(62.4)$ & $1152(50.8)$ & $74(77.7)$ & 572(58.9) & $848(49.6)$ & $120(66.5)$ & 1540(53.9) \\
\hline $\begin{array}{l}\text { Traditional } \\
\text { methods }\end{array}$ & $70(14.4)$ & $325(16.3)$ & $6(8.5)$ & $129(14.4)$ & $243(16.2)$ & 29(16.8) & 401(15.7) \\
\hline $\begin{array}{l}\text { Modern } \\
\text { methods }\end{array}$ & $124(23.2)$ & 686(32.9) & 14(13.8) & 239(26.7) & $555(34.2)$ & $30(16.8)$ & 824(30.4) \\
\hline
\end{tabular}

Data presented as n (\%). The percentage is adjusted for sample weight 
Table 3: Adjusted odds ratios showing the effect of men's FP perceptions on their partner's FP demand: results from logistic regression, $(\mathrm{n}=7747)$

\begin{tabular}{|c|c|c|c|c|c|}
\hline \multirow[t]{2}{*}{ Variables } & \multicolumn{5}{|c|}{ Adjusted OR(95\% CI) } \\
\hline & Model 0 & Model 1 & Model 2 & Model 3 & Model 4 \\
\hline \multicolumn{6}{|c|}{ PARTNER'S FP PERCEPTION } \\
\hline \multicolumn{6}{|c|}{$\begin{array}{l}\text { Contraception is woman's business, man } \\
\text { shouldn't worry } \\
\text { Disagree (Ref) }\end{array}$} \\
\hline Agree & $0.95(0.83-1.08)$ & $1.04(0.90-1.19)$ & $1.06(0.92-1.22)$ & $1.06(0.92-1.22)$ & $1.05(0.92-1.22)$ \\
\hline Don’t know & $0.87(0.64-1.18)$ & $0.92(0.67-1.28)$ & $0.94(0.68-1.30)$ & $0.93(0.67-1.29)$ & $0.94(0.68-1.30)$ \\
\hline \multicolumn{6}{|c|}{$\begin{array}{l}\text { Women who use contraception becomes } \\
\text { promiscuous } \\
\text { Disagree (Ref) }\end{array}$} \\
\hline Agree & $0.64(0.59-0.72)$ & $0.84(0.74-0.94)$ & $0.86(0.76-0.97)$ & $0.86(0.76-0.97)$ & $0.86(0.76-0.97)$ \\
\hline Don’t know & $0.69(0.55-0.86)$ & $1.04(0.81-1.34)$ & $1.09(0.85-1.41)$ & $1.10(0.86-1.42)$ & $1.09(0.85-1.41)$ \\
\hline \multicolumn{6}{|c|}{ WOMAN'S CHARACTERISTICS } \\
\hline \multicolumn{6}{|c|}{ Age (years) } \\
\hline \multicolumn{6}{|l|}{$<30(\operatorname{Ref})$} \\
\hline 30-39 & & $1.22(1.36-1.83)$ & 1.19(1.05-1.36) & 1.18(1.04-1.35) & $1.24(1.07-1.43)$ \\
\hline$\geq 40$ & & 2.56(2.27-3.15) & 2.49(1.99-3.13) & 2.45(1.95-3.08) & 2.61(2.05-3.34) \\
\hline \multicolumn{6}{|l|}{ Highest educational level } \\
\hline \multicolumn{6}{|l|}{ No education (Ref) } \\
\hline Primary & & $1.75(1.07-1.39)$ & 1.54(1.31-1.80) & 1.53(1.30-1.79) & $1.56(1.32-1.84)$ \\
\hline Secondary & & 2.41(2.05-3.22) & $1.93(1.62-2.30)$ & $1.91(1.60-2.28)$ & $1.91(1.58-2.30)$ \\
\hline Higher & & 2.53(2.01-3.19) & $2.02(1.53-2.67)$ & $1.20(1.51-2.64)$ & $1.90(1.41-2.55)$ \\
\hline \multicolumn{6}{|c|}{$\begin{array}{l}\text { Number of living children incl. current } \\
\text { pregnancy } \\
\text { No child (Ref) }\end{array}$} \\
\hline $1-2$ & & $2.75(2.06-3.68)$ & 2.75(2.05-3.68) & $2.76(2.06-3.69)$ & $2.81(2.09-3.76)$ \\
\hline 3-4 & & 4.17(3.10-5.60) & 4.15(3.08-5.57) & 4.15(3.09-5.59) & 4.29(3.18-5.79) \\
\hline 5 or more & & 4.73(3.47-6.47) & 4.74(3.46-6.49) & 4.78(3.49-6.54) & $4.93(3.59-6.78)$ \\
\hline \multicolumn{6}{|l|}{ Religion } \\
\hline \multicolumn{6}{|l|}{ Catholic (Ref) } \\
\hline Protestant & & $1.02(0.84-1.24)$ & $0.99(0.81-1.20)$ & $0.99(0.82-1.21)$ & $0.98(0.80-1.19)$ \\
\hline Islam & & $0.59(0.48-0.73)$ & $0.58(0.47-0.72)$ & $0.60(0.48-0.74)$ & $0.58(0.46-0.71)$ \\
\hline Traditional/Others & & $0.52(0.32-0.83)$ & $0.51(0.32-0.81)$ & $0.51(0.32-0.82)$ & $0.49(0.31-0.79)$ \\
\hline \multicolumn{6}{|l|}{ Place of residence } \\
\hline \multicolumn{6}{|l|}{ Urban (Ref) } \\
\hline Rural & & $0.80(0.71-0.90)$ & $0.95(0.83-1.08)$ & $0.95(0.83-1.09)$ & $0.94(0.82-1.08)$ \\
\hline \multicolumn{6}{|l|}{ Region of residence } \\
\hline \multicolumn{6}{|l|}{ South (Ref) } \\
\hline North & & $0.69(0.61-0.80)$ & $0.76(0.66-0.88)$ & $0.76(0.66-0.88)$ & $0.75(0.65-0.86)$ \\
\hline \multicolumn{6}{|l|}{ Occupation } \\
\hline \multicolumn{6}{|l|}{ Unemployed (Ref) } \\
\hline Professional/Managerial & & & $0.96(0.75-1.27)$ & $0.95(0.71-1.26)$ & $0.97(0.73-1.28)$ \\
\hline Agricultural-related & & & 1.25(1.03-1.51) & 1.24(1.01-1.51) & $1.25(1.03-1.52)$ \\
\hline Others & & & $1.10(0.97-1.24)$ & $1.10(0.95-1.27)$ & $1.10(0.97-1.25)$ \\
\hline Household wealth index & & & & & \\
\hline Poorest (Ref) & & & & & \\
\hline Poorer & & & $0.90(0.75-1.07)$ & $0.89(0.75-1.06)$ & $0.90(0.76-1.08)$ \\
\hline Middle & & & 1.34(1.12-1.61) & 1.33(1.11-1.60) & $1.35(1.11-1.64)$ \\
\hline Richer & & & $1.60(1.28-1.93)$ & 1.56(1.27-1.91) & $1.58(1.26-1.97)$ \\
\hline Richest & & & $1.75(1.37-2.23)$ & $1.72(1.35-2.19)$ & $1.73(1.33-2.25)$ \\
\hline Decision making power & & & & & \\
\hline Poor $(R e f)$ & & & & & \\
\hline Moderate & & & & $0.97(0.82-1.14)$ & \\
\hline Good & & & & $1.10(0.93-1.30)$ & \\
\hline MALE PARTNER'S CI & & & & & \\
\hline Partner's age (years) & & & & & \\
\hline$<30(\operatorname{Ref})$ & & & & & \\
\hline $30-39$ & & & & & $0.96(0.82-1.12)$ \\
\hline$\geq 40$ & & & & & $0.91(0.75-1.10)$ \\
\hline
\end{tabular}


No education (Ref)

Primary

0.93(0.78-1.10)

Secondary

0.96(0.80-1.15)

Higher

1.14(0.90-1.45)

Partner's occupation

Unemployed (Ref)

Professional/Managerial

0.59(0.37-0.94)

Agricultural-related

$0.66(0.42-1.03)$

Others

$0.65(0.42-1.01)$

FP: family planning; Data presented as Odd Ratio (95\% CI)

BOLD (statistically significant at $\mathrm{p}<0.05$ ) 
Table 4: Adjusted multinomial regression model of partner's perception of contraception and the uptake of modern methods among women with a demand, (n=2765)

\begin{tabular}{|c|c|c|c|c|c|c|c|c|c|c|}
\hline \multirow[t]{2}{*}{ Variables } & \multicolumn{2}{|c|}{ Model 0} & \multicolumn{2}{|c|}{ Model 1} & \multicolumn{2}{|c|}{ Model 2} & \multicolumn{2}{|c|}{ Model 3} & \multicolumn{2}{|c|}{ Model 4} \\
\hline & Traditional & Modern & Traditional & Modern & Traditional & Modern & Traditional & Modern & Traditional & Modern \\
\hline \multicolumn{11}{|c|}{ PARTNER'S FP PERCEPTION } \\
\hline \multicolumn{11}{|c|}{$\begin{array}{l}\text { Contraception is woman's business, } \\
\text { man shouldn't worry }\end{array}$} \\
\hline \multicolumn{11}{|l|}{ Disagree (Ref) } \\
\hline Agree & $0.84(0.62-1.14)$ & $0.79(0.62-1.01)$ & $0.86(0.61-1.21)$ & $0.84(0.64-1.10)$ & $0.87(0.62-1.22)$ & $0.87(0.66-1.14)$ & $0.84(0.59-1.18)$ & $0.86(0.65-1.13)$ & $0.85(0.60-1.20)$ & $0.86(0.66-1.14)$ \\
\hline Don’t know & $0.21(0.08-0.52)$ & $0.50(0.25-1.00)$ & $0.21(0.08-0.58)$ & $0.56(0.26-1.19)$ & $0.22(0.08-0.62)$ & $0.61(0.28-1.31)$ & $0.19(0.07-0.53)$ & $0.54(0.25-1.17)$ & $0.20(0.07-0.55)$ & $0.58(0.27-1.26)$ \\
\hline \multicolumn{11}{|c|}{$\begin{array}{l}\text { Women who use contraception } \\
\text { becomes promiscuous } \\
\text { Disagree (Ref) }\end{array}$} \\
\hline Agree & $0.84(0.65-1.09)$ & $0.69(0.57-0.84)$ & $1.28(0.97-1.70)$ & $0.92(0.74-1.15)$ & $1.34(1.01-1.78)$ & $0.98(0.78-1.22)$ & $1.34(1.01-1.77)$ & $0.97(0.77-1.21)$ & $1.34(1.01-1.79)$ & $0.97(0.78-1.22)$ \\
\hline Don’t know & $1.46(0.89-2.39)$ & $0.53(0.32-0.87)$ & $3.14(1.76-5.60)$ & $0.90(0.51-1.56)$ & $3.45(1.92-6.21)$ & $0.95(0.54-1.67)$ & $3.75(2.07-6.81)$ & $1.03(0.58-1.81)$ & $3.84(2.11-7.02)$ & $1.09(0.62-1.93)$ \\
\hline \multicolumn{11}{|c|}{ WOMAN'S CHARACTERISTICS } \\
\hline \multicolumn{11}{|l|}{ Age (years) } \\
\hline \multicolumn{11}{|l|}{$<30(R e f)$} \\
\hline 30-39 & & & $1.39(1.02-1.88)$ & $1.80(1.41-2.30)$ & $1.34(0.98-1.840$ & $1.68(1.31-2.16)$ & $1.24(0.91-1.71)$ & $1.60(1.24-2.06)$ & $1.10(0.78-1.55)$ & $1.51(1.14-1.99)$ \\
\hline$\geq 40$ & & & $1.63(1.03-2.57)$ & 2.29(1.61-3.27) & $1.58(1.00-2.51)$ & $2.12(1.48-3.04)$ & $1.45(0.91-2.31)$ & $1.99(1.39-2.87)$ & $1.15(0.68-1.92)$ & $1.77(1.18-2.65)$ \\
\hline \multicolumn{11}{|c|}{ Highest educational level } \\
\hline \multicolumn{11}{|c|}{ No education (Ref) } \\
\hline Primary & & & $1.86(1.15-3.01)$ & $4.22(2.99-5.94)$ & $1.41(0.85-2.34)$ & $3.13(2.19-4.47)$ & $1.31(0.79-2.18)$ & $2.86(1.99-4.10)$ & $1.23(0.72-2.10)$ & $2.43(1.66-3.54)$ \\
\hline Secondary & & & $2.61(1.64-4.17)$ & 5.03(3.56-7.12) & $1.78(1.07-2.95)$ & $3.27(2.26-4.74)$ & $1.73(1.04-2.87)$ & $3.06(2.11-4.45)$ & $1.61(0.93-2.78)$ & $2.55(1.72-3.80)$ \\
\hline Higher & & & $4.90(2.82-8.52)$ & $\begin{array}{l}\text { 7.45(4.83- } \\
11.47)\end{array}$ & $3.63(1.93-6.82)$ & $4.62(2.81-7.60)$ & $3.46(1.84-6.52)$ & $4.28(2.59-7.06)$ & $3.16(1.60-6.27)$ & $3.32(1.95-5.66)$ \\
\hline \multicolumn{11}{|c|}{$\begin{array}{l}\text { Number of living children incl. current } \\
\text { pregnancy } \\
\text { No child (Ref) }\end{array}$} \\
\hline $1-2$ & & & $1.51(0.59-3.89)$ & $1.30(0.60-2.79)$ & $1.47(0.57-3.81)$ & $1.27(0.59-2.77)$ & $1.31(0.51-3.40)$ & $1.24(0.57-2.69)$ & $1.14(0.44-2.97)$ & $1.15(0.53-2.52)$ \\
\hline $3-4$ & & & $1.76(0.68-4.58)$ & $1.41(0.65-3.04)$ & $1.69(0.65-4.45)$ & $1.35(0.62-2.95)$ & $1.53(0.58-4.00)$ & $1.31(0.60-2.87)$ & $1.28(0.48-3.39)$ & $1.22(0.55-2.70)$ \\
\hline 5 or more & & & $1.13(0.42-3.02)$ & $1.10(0.50-2.43)$ & $1.11(0.41-3.00)$ & $1.13(0.51-2.53)$ & $1.02(0.38-2.76)$ & $1.13(0.50-2.52)$ & $0.82(0.30-2.25)$ & $1.01(0.45-2.30)$ \\
\hline \multicolumn{11}{|l|}{ Religion } \\
\hline \multicolumn{11}{|l|}{ Catholic (Ref) } \\
\hline Protestant & & & $0.55(0.38-0.78)$ & $0.81(0.60-1.09)$ & $0.54(0.37-0.77)$ & $0.81(0.60-1.10)$ & $0.53(0.37-0.76)$ & $0.81(0.60-1.09)$ & $0.53(0.37-0.76)$ & $0.80(0.59-1.09)$ \\
\hline Islam & & & $0.41(0.27-0.62)$ & $0.54(0.39-0.75)$ & $0.39(0.26-0.60)$ & $0.52(0.37-0.73)$ & $0.44(0.29-0.67)$ & $0.58(0.41-0.81)$ & $0.44(0.29-0.68)$ & $0.59(0.42-0.83)$ \\
\hline Traditional/Others & & & $0.44(0.17-1.11)$ & $0.43(0.19-0.97)$ & $0.52(0.20-1.33)$ & $0.50(0.22-1.12)$ & $0.53(0.21-1.35)$ & $0.50(0.22-1.14)$ & $0.50(0.19-1.29)$ & $0.49(0.22-1.11)$ \\
\hline
\end{tabular}


Table 4: continued

\begin{tabular}{|c|c|c|c|c|c|c|c|c|c|c|}
\hline \multirow[t]{2}{*}{ Variables } & \multicolumn{2}{|c|}{ Model 0} & \multicolumn{2}{|c|}{ Model 1} & \multicolumn{2}{|c|}{ Model 2} & \multicolumn{2}{|c|}{ Model 3} & \multicolumn{2}{|c|}{ Model 4} \\
\hline & Traditional & Modern & Traditional & Modern & Traditional & Modern & Traditional & Modern & Traditional & Modern \\
\hline \multicolumn{11}{|l|}{ Place of residence } \\
\hline \multicolumn{11}{|l|}{ Urban (Ref) } \\
\hline Rural & & & $0.53(0.41-0.69)$ & $0.46(0.38-0.57)$ & $0.67(0.51-0.90)$ & $0.60(0.48-0.76)$ & $0.71(0.53-0.95)$ & $0.62(0.49-0.78)$ & $0.69(0.52-0.93)$ & $0.59(0.47-0.75)$ \\
\hline \multicolumn{11}{|l|}{ Region of residence } \\
\hline \multicolumn{11}{|l|}{ South (Ref) } \\
\hline North & & & $0.23(0.17-0.32)$ & $0.85(0.68-1.05)$ & $0.28(0.20-0.38)$ & $0.98(0.78-1.23)$ & $0.30(0.21-0.41)$ & $1.05(0.83-1.32)$ & $0.29(0.20-0.40)$ & $1.01(0.80-1.28)$ \\
\hline \multicolumn{11}{|l|}{ Occupation } \\
\hline \multicolumn{11}{|l|}{ Unemployed (Ref) } \\
\hline Professional/Managerial & & & & & $0.79(0.45-1.40)$ & $1.20(0.76-1.88)$ & $0.61(0.34-1.09)$ & $1.02(0.64-1.61)$ & $0.57(0.31-1.02)$ & $0.96(0.60-1.52)$ \\
\hline Agricultural-related & & & & & $1.38(0.86-2.22)$ & $1.25(0.87-1.78)$ & $1.17(0.73-1.90)$ & $1.07(0.75-1.54)$ & $1.11(0.68-1.82)$ & $1.00(0.69-1.44)$ \\
\hline Others & & & & & $1.22(0.87-1.72)$ & $1.38(1.06-1.80)$ & $1.00(0.70-1.42)$ & $1.20(0.92-1.58)$ & $0.99(0.70-1.41)$ & $1.20(0.91-1.57)$ \\
\hline \multicolumn{11}{|l|}{ Household wealth index } \\
\hline \multicolumn{11}{|l|}{ Poorest $(R e f)$} \\
\hline Poorer & & & & & $1.28(0.59-2.79)$ & $3.31(1.81-6.03)$ & $1.21(0.55-2.64)$ & 3.18(1.74-5.81) & $1.17(0.53-2.58)$ & $2.95(1.60-5.43)$ \\
\hline Middle & & & & & $1.65(0.79-3.44)$ & $3.98(2.21-7.14)$ & $1.57(0.75-3.28)$ & $3.79(2.11-6.82)$ & $1.44(0.67-3.10)$ & $3.29(1.80-6.01)$ \\
\hline Richer & & & & & $2.89(1.39-6.01)$ & 4.44(2.45-8.08) & $2.79(1.34-5.82)$ & $4.23(2.32-7.72)$ & 2.56(1.17-5.58) & $3.70(1.98-6.91)$ \\
\hline Richest & & & & & $3.08(1.42-6.65)$ & $6.01(3.20-11.28)$ & $2.87(1.32-6.23)$ & $5.58(2.97-10.51)$ & $2.57(1.12-5.89)$ & $4.73(2.44-9.18)$ \\
\hline \multicolumn{11}{|l|}{ Decision making power } \\
\hline \multicolumn{11}{|l|}{ Poor (Ref) } \\
\hline Moderate & & & & & & & $1.19(0.81-1.74)$ & $1.51(1.15-1.98)$ & $1.09(0.71-1.75)$ & $1.51(1.14-1.98)$ \\
\hline Good & & & & & & & $2.23(1.55-3.20)$ & $1.95(1.49-2.55)$ & $2.24(1.56-3.23)$ & $1.96(1.49-5.57)$ \\
\hline \multicolumn{11}{|l|}{ Partner's age (years) } \\
\hline \multicolumn{11}{|l|}{$<30($ Ref $)$} \\
\hline 30-39 & & & & & & & & & $1.09(0.71-1.68)$ & $0.98(0.70-1.37)$ \\
\hline$\geq 40$ & & & & & & & & & $1.44(0.87-2.39)$ & $1.11(0.75-1.65)$ \\
\hline \multicolumn{11}{|c|}{ Partner's highest educational level } \\
\hline \multicolumn{11}{|c|}{ No education (Ref) } \\
\hline Primary & & & & & & & & & $1.18(0.62-2.24)$ & $1.67(1.05-2.68)$ \\
\hline Secondary & & & & & & & & & $1.36(0.71-2.58)$ & $1.82(1.14-2.91)$ \\
\hline Higher & & & & & & & & & $1.27(0.62-2.59)$ & $2.02(1.20-3.40)$ \\
\hline \multicolumn{11}{|l|}{ Partner's occupation } \\
\hline \multicolumn{11}{|l|}{ Unemployed (Ref) } \\
\hline Professional/Managerial & & & & & & & & & $2.84(0.85-9.51)$ & 2.79(1.05-7.39) \\
\hline Agricultural-related & & & & & & & & & $2.47(0.74-8.21)$ & $2.81(1.07-7.35)$ \\
\hline Others & & & & & & & & & $2.16(0.67-6.98)$ & $2.29(0.89-5.89)$ \\
\hline
\end{tabular}




\section{Figure caption list}

Figure 1: Count of cases from the 2013 NDHS Couple's data (\% weighted)

Figure 2: Partner's FP perception and spousal method choice 


\section{Figure 1:}

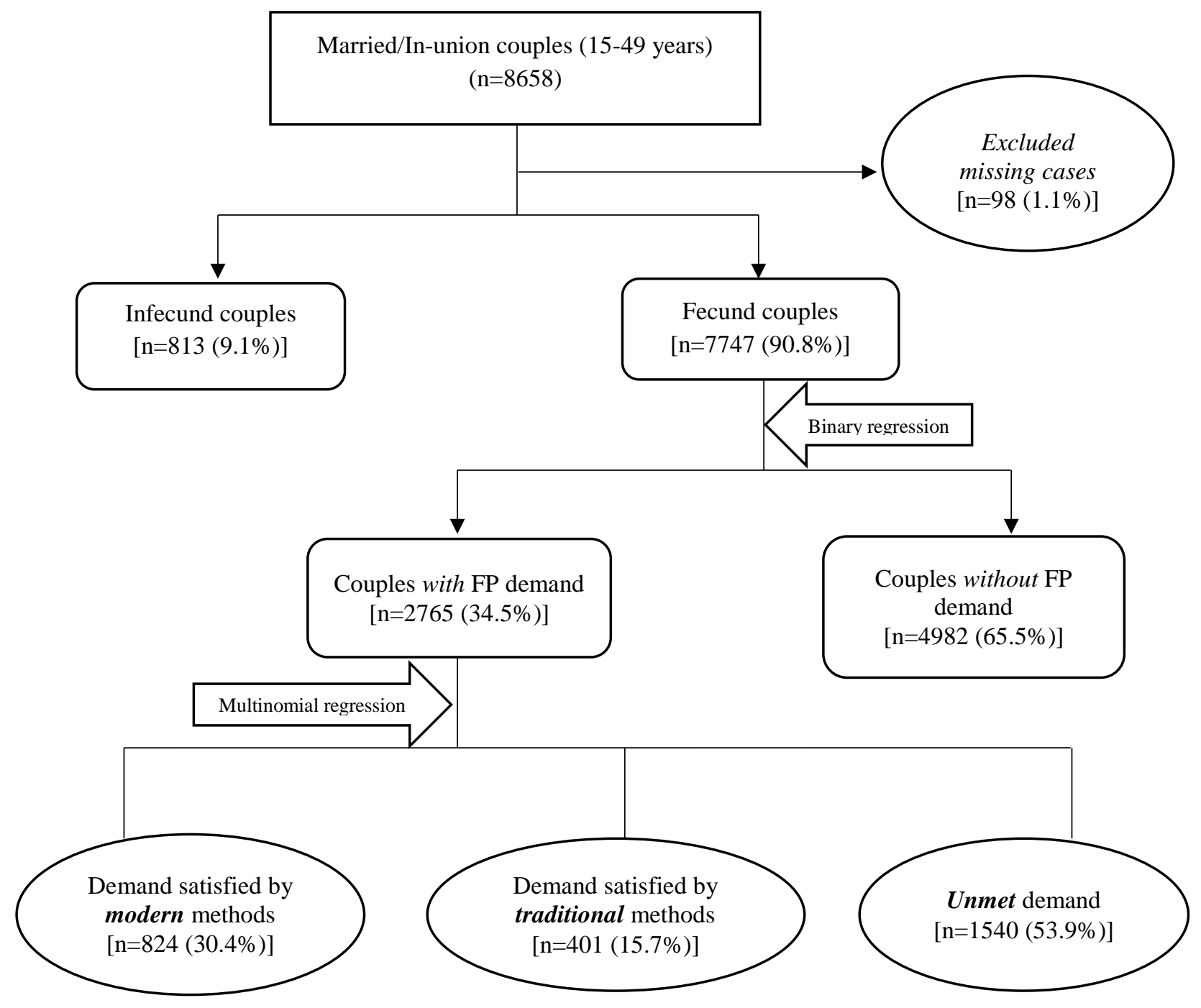




\section{Figure 2}

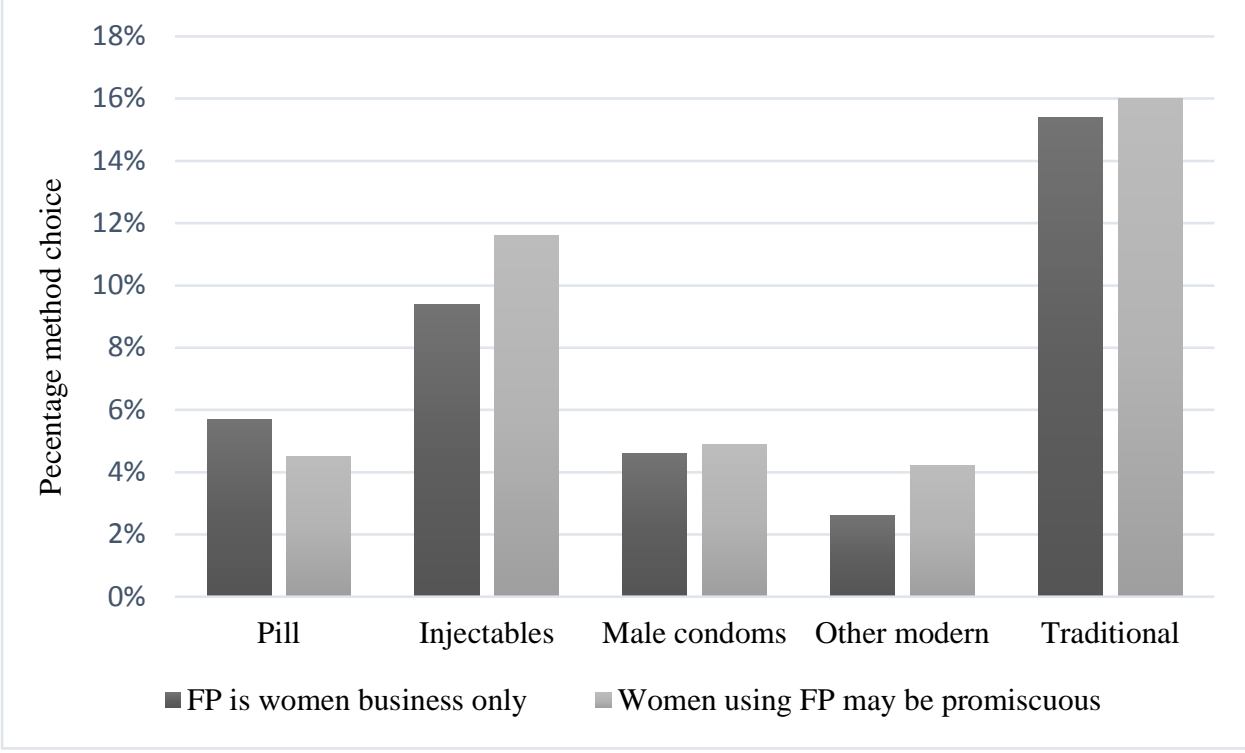

